\title{
Forensic Browser of Twitter based on Web Services
}

\author{
Revani Saputra \\ Department of Information Systems \\ Universitas Ahmad Dahlan \\ Yogyakarta of Indonesia
}

\author{
Imam Riadi \\ Department of Information Systems \\ Universitas Ahmad Dahlan \\ Yogyakarta of Indonesia
}

\begin{abstract}
Twitter is a social media that can be accessed through smartphones and desktops. The large number of users makes Twitter inseparable from crimes including pornography, online gambling and hate speech. In this study, the steps used are collection, examination and analysis. This study uses a laptop as an object that is scenario in a state of opening Twitter via the Google Chrome browser with two modes, namely public mode and private mode. The research used the help of forensic tools, namely ftk imager, dumpIT, belkasoft ram capturer, $\mathrm{XhD}$, browser history viewer, browser history capturer, and cached video viewer. This research produces digital evidence with google chrome browser in public mode and google chrome browser in private mode. In the condition of using the browser in public mode with indicators in the form of text posts, link posts, images, and videos, the research succeeded in getting all the evidence that was sought. Meanwhile, in the private mode google chrome browser managed to get evidence with a success of $50 \%$, namely in the form of text posts and link posts. While the remaining 50\% is not found for private mode browsers, namely in image posts and video posts.
\end{abstract}

\section{Keywords}

Forensics, Web, Browsers, Pornography, Twitter

\section{INTRODUCTION}

Social media has become a necessity for communication tools most often used by society today, social media can penetrate distance, space and time. In 2019, the number of social media users in Indonesia has reached 150 million users, equivalent to a penetration rate of $56 \%$ [1]. One of the social media that is often used by the community is Twitter [2]. Twitter is a microblogging social media that can be accessed through desktop, web, Android and iOS platforms [3]. The large number of users makes social media usable for criminal activities. Cybercrime can occur due to advances in computer technology and information technology, especially internet media [4]. Some examples of crimes involving social media are cyberbulying, defamation, and the distribution of pornographic content. Pornography is any form of audio, visual, and audio-visual material that focuses on genitals and sexual behavior for sexual pleasure and pleasure [5]. These crimes can be uncovered with the help of digital forensics. In general, digital forensics can be divided into 4 stages, namely collection, maintenance, analysis and presentation [6].

\subsection{Literature Review}

\subsubsection{Previous Studies}

Rusydi Umar and Anton Yudhana (2018) have conducted digital forensic research entitled "Comparative Design of Live Forensics on Social Media Security of Instagram, Facebook and Twitter in Windows 10". The research design involved three social media to carry out safety comparisons, namely Facebook, Instagram and Twitter. All social media accounts involved in the research design are newly created accounts or special accounts for research use [7].

Muhammad Nur Faiz, Rusydi Umar, Anton Yudhana (2017) conducted a digital forensic research entitled "Implementation of Live Forensics for Comparison of Browsers in Email Security". The results show that in public mode only Google Chrome does not get the password, while in private mode the three browsers display the same results for the password, which is not visible [8].

Anton Yudhana, Imam Riadi, and Ikhsan Zuhriyanto (2019) have completed a research entitled "Analysis of Live Forensics for Social Media Applications in Browsers Using the Digital Forensics Research Workshop (DFRWS) method". This research has succeeded in obtaining evidence in the form of deleted images on twitter posts. To ensure that the images found are the results of posts from the account in question, the research was conducted to match the user id [9].

Tayomi Dwi Larasati and Bekti Cahyo Hidayanto (2017) have conducted a study in the field of digital forensics with the title "Live Forensics Analysis for Comparison of Instant Messenger Applications on the Windows 10 Operating System". Through this research, it was found that Facebook and Line Messenger were successfully foensicized, while the Telegram Messenger application was an application that had its own challenges for the forensic world because existing data had a level of confidentiality that was more secure than Facebook and Line Messenger [10].

Ermadi Satriya Wijaya and Teguh Subagyo (2018) have successfully conducted a study entitled "Analysis of Digital Evidence on Android Random Access Memory Using the Live Forensic Method of Child Abduction Cases". This research succeeded in finding digital evidence in the form of images sent by the perpetrator, previously deleted text messages and $\log$ files of incoming calls on the victim's smartphone and log files of outgoing calls on the perpetrator's smartphone. However, there are some data that cannot be found, such as time and voice calls [11].

\subsubsection{Web Browser}

A web browser is a program that can be used to retrieve HTML documents from web server applications that can be used to search and find various information, send and receive e-mails, communicate with instant messengers or social networks, make buying and selling transactions through ewebsites. commerce [12]. Popular web browsers include Mozilla Firefox, Internet Explorer, Google Chrome, and Opera [13].

\subsubsection{Social media}

Social media is a form of rapid technological development. Based on the results of a survey conducted by We Are Social and Hootsuite in 2019 as can be seen in Figure 1. 


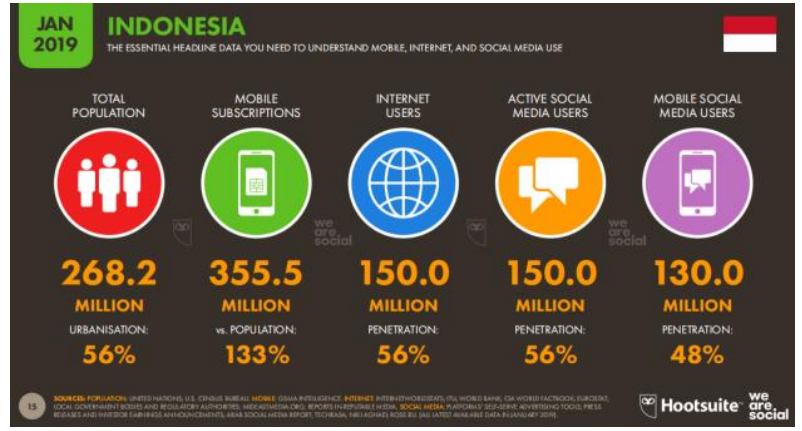

Figure 1. Social Media Users in Indonesia

Figure 1 states that active social media users have increased by $7 \%$ from the previous year or $56 \%$ of the total population of Indonesia. This is directly proportional to the increasing number of internet users in Indonesia [14].

\subsubsection{Twitter}

Twitter is a website that offers social networking services in the form of microblogs to users, allowing users to send and read a post to the public called a tweet. On Twitter, users can also upload media other than text, such as images and videos, called tweetpics [15]. The amount of public interest in this service has made many parties use it for certain interests. Apart from that, users can also use the \# sign (hashtag) to compose messages based on topic.

\subsubsection{Digital Forensics}

Digital forensics means a search activity that goes through the process of identification, filtering and documentation which has the power to support evidence of facts [16].The purpose of digital forensics is to prove the existence of an instruction that has occurred by investigating the crime scene (crime scene) so that it can prove from evidence such as computer systems, storage media, electronic documents, or data packets moving through computer networks. [17].

\subsubsection{Digital Evidence}

Digital evidence is all data and information obtained in digital form such as images, sounds, text, symbols, numbers, etc. One of the main steps in investigating a crime is collecting digital evidence [18]. Digital evidence is so susceptible to change that it can be affected if it is handled incorrectly. If the evidence has changed, it will lead to false results or the evidence will be useless. Digital evidence is very necessary for a standardized process and formalized so that digital evidence can be accepted during the trial process [19].

\subsubsection{Pornography}

Pornography is images, sketches, illustrations, photographs, writings, voices, sounds, moving pictures, animation, cartoons, conversations, gestures, or other forms of messages through various forms of communication media and / or public performances, which contain obscenity or exploitation. sex that violates the norms of decency in society [20]. Pornography can be traded, for example, downloading videos on the internet and then trading in the surrounding community. One of the factors in the development of the spread of pornographic content is the increasingly advanced technology, especially the internet [21].

\section{METHODOLOGY}

\subsection{Research Scenario}

The case used in this study is the distribution of pornographic content through Twitter social media. The pornography in question can be in the form of regular posts or posts that lead to transactions. Twitter account owners post several posts that show pornographic content activity and even account owners are trading the content. Then the post was deleted from Twitter to eliminate digital traces as can be seen in Figure 2.

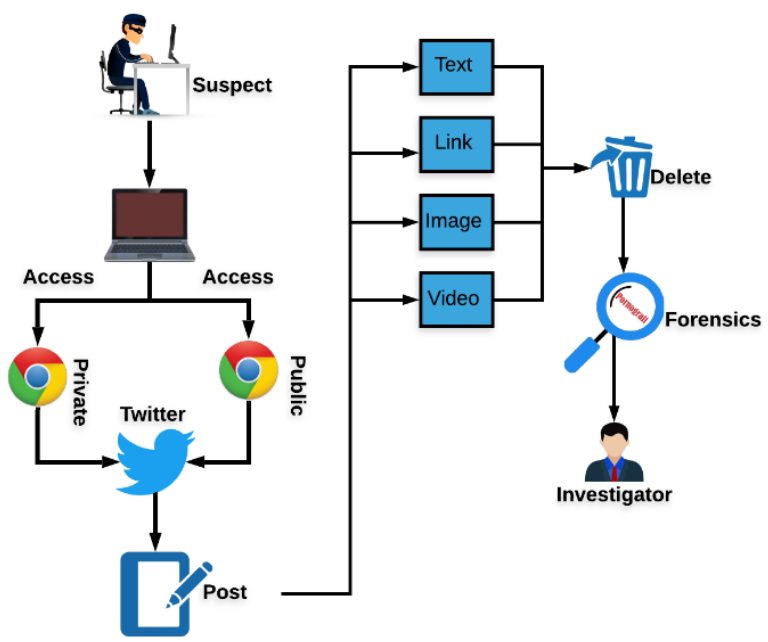

Figure 2. Research Scenarios

Figure 2 explains that the scenario uses two browser usage models, namely a private browser and a public browser. The twitter account used in this study is a special account created for research purposes with the username @ forensiksatu.

\subsection{Research Stages}

In this implementation stage, the investigator carries out a series of activities to obtain information in accordance with procedures. The stages or methods used in finding evidence are collection, examination and analysis. These stages can be seen in Figure 3.

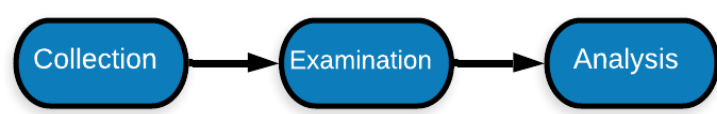

Figure 3. Stages of the Method

The steps to be taken by the investigator in seeking information as evidence are described as follows.

\subsubsection{Collection}

The evidence that was successfully obtained was a laptop that was scenarioed as evidence of a crime. As can be seen in table 1.

Table 1. Physical Evidence

\begin{tabular}{|c|c|c|c|}
\hline No & Name & Picture & Information \\
\hline 1 & Laptop & & $\begin{array}{l}\text { Lenovo G40- } 45 \text { found } \\
\text { at the scene of the } \\
\text { crime scene with the } \\
\text { power on and } \\
\text { connected to the } \\
\text { network }\end{array}$ \\
\hline 2 & $\begin{array}{l}\text { Chargi } \\
\text { ng } \\
\text { Cable }\end{array}$ & & $\begin{array}{l}\text { The actor's Lenovo } \\
\text { G40- } 45 \text { charger cable } \\
\text { with input } 100-240 \mathrm{~V} \\
\sim 1.8 \mathrm{~A} \text { and outputs } \\
20 \mathrm{~V} \text { and } 3.25 \mathrm{~A}\end{array}$ \\
\hline
\end{tabular}

Evidence that has been collected is then carried out data acquisition, especially for temporary data first. 


\subsubsection{Examination}

At this stage, the process of taking over the information contained in the perpetrator's laptop will be carried out. Prioritized data is data that is temporary, such as RAM activity. The acquisition process is carried out in two stages, namely the public mode browser and the incognito mode browser.

\subsubsection{Analysis}

The analysis in question is the process of searching for information that is from the previous data acquisition. The information you are looking for is text posts, link posts, image posts, and video posts.

\section{RESULT AND DISCUSSION}

The scenario of the case of spreading pornographic content on social media, Twitter, tries to be uncovered by doing forensics on physical evidence, namely the alleged perpetrator's laptop. The tools and materials needed, among others, can be seen in table 2 .

Table 2. Tools and Materials

\begin{tabular}{|c|c|c|}
\hline No. & $\begin{array}{l}\text { Tools } \\
\text { Materials }\end{array}$ & Information \\
\hline 1 & Laptop 1 & $\begin{array}{l}\text { The investigator's laptop Intel (R) } \\
\text { Core (TM) i5-7500HQ CPU @ } \\
2.50 \mathrm{GHz} \text { (4 CPUs), } 2.5 \mathrm{GHz}\end{array}$ \\
\hline 2 & Laptop 2 & $\begin{array}{l}\text { The alleged perpetrator's laptop, } \\
\text { namely Lenovo Ram 4GB, AMD } \\
\text { A8-6410, Model G40-45, } \\
\text { Windows } 10 \text { Home x64 }\end{array}$ \\
\hline 3 & FTK Imager & $\begin{array}{l}\text { To read the capture result from } \\
\text { the ram capturer and use it to } \\
\text { check the hash value of the ram } \\
\text { acquisition result }\end{array}$ \\
\hline 4 & $\begin{array}{l}\text { Belkasoft Ram } \\
\text { Capturer }\end{array}$ & $\begin{array}{l}\text { To carry out the acquisition of } \\
\text { ram }\end{array}$ \\
\hline 5 & DumpIT & $\begin{array}{l}\text { To carry out the acquisition of } \\
\text { ram }\end{array}$ \\
\hline 6 & $\mathrm{XhD}$ & $\begin{array}{l}\text { To read the results of the ram } \\
\text { acquisition from the DumpIT tool }\end{array}$ \\
\hline 7 & $\begin{array}{l}\text { Browser History } \\
\text { Viewer }\end{array}$ & $\begin{array}{l}\text { To read the capture result from } \\
\text { the Browser History Capturer } \\
\text { tool }\end{array}$ \\
\hline 8 & $\begin{array}{l}\text { Browser History } \\
\text { Capturer }\end{array}$ & $\begin{array}{l}\text { To retrieve history from the } \\
\text { browser including cached images } \\
\text { and the web }\end{array}$ \\
\hline 9 & $\begin{array}{l}\text { Cached Video } \\
\text { Viewer }\end{array}$ & $\begin{array}{l}\text { To get evidence that is in video } \\
\text { form. }\end{array}$ \\
\hline 10 & $\begin{array}{l}\text { Media Player } \\
\text { Classical Home } \\
\text { Cinema }\end{array}$ & $\begin{array}{l}\text { To open the acquisition results } \\
\text { from the Cached Video Viewer } \\
\text { tool }\end{array}$ \\
\hline
\end{tabular}

\subsection{Acquisition}

This stage of the acquisition is carried out using four different tools. Temporary data is acquired using the DumpIT and Ram Capturer tools, while data that can still be accessed when the laptop is dead is acquired using the help of forensic tools, the video cache viewer and browser history capturer. The acquisition process is carried out for two models, namely the use of the public mode browser and the incognito mode browser.

\subsubsection{Belkasoft Ram Capturer}

Belkasoft ram capturer is used to acquire ongoing ram activities. The acquisition process can be seen in Figure 4 .

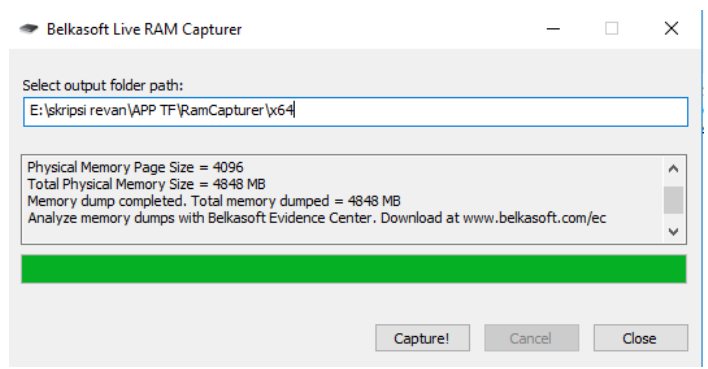

Figure 4. Acquisition with ram capturer

Figure 4 shows the acquisition process by the ram capturer and then produces data with the .mem extension.

\subsubsection{DumpIT}

The acquisition using the DumpIt tool can be seen as shown in Figure 5.

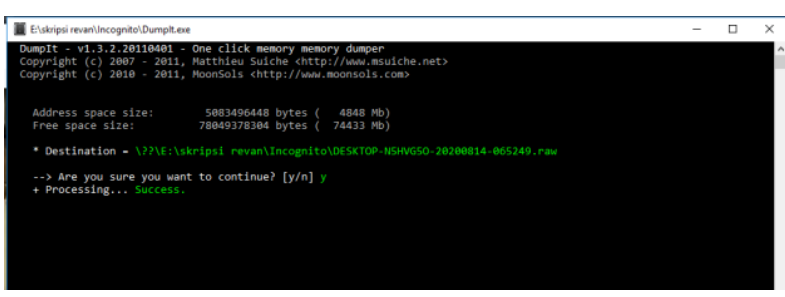

Figure 5. Acquisition with DumpIT

The resulting file has a .mem extension and a name that is automatically given by the tool according to the date and the laptop user.

\subsubsection{Browser History Capturer}

The acquisition process can be seen in Figure 6 .

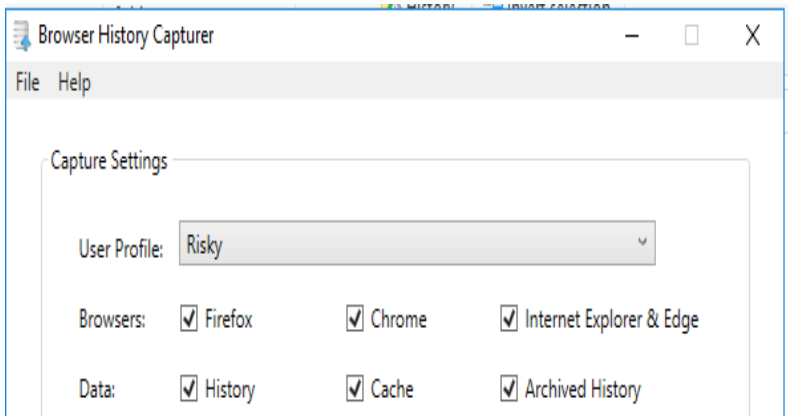

Figure 6. Acquisition with Browser History Capturer

Acquisition can choose three browsers at once, namely Firefox, Chrome, Internet Explorer \& Edge or can choose one of them.

\subsubsection{Video Cache Viewer}

The video cache viewer will automatically capture the video cache from the browser when the tool is run. The acquisition process with a video cache viewer can be seen as shown in Figure 7. 


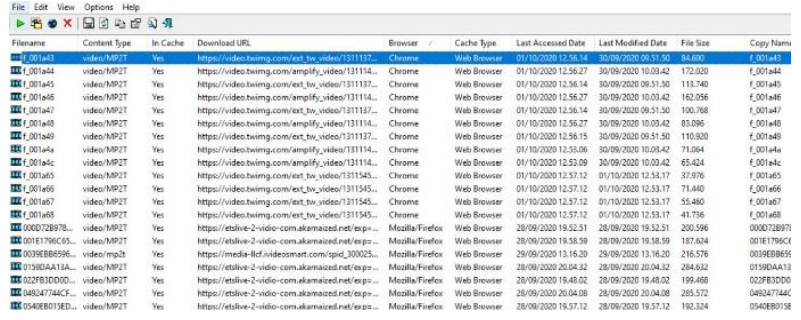

Figure 7. Video Cache Viewer Acquisition

Some of the information that can be seen includes the url of the video and the browser used.

\subsection{Analysis}

\subsubsection{Public Mode Browser}

Data analysis was carried out on the acquisition result file in the previous stage.

\subsubsection{Belkasoft Ram Capturer}

The results of the acquisition using belkasoft ram capturer were then analyzed using the FTK Imager tool. The following is evidence found using the FTK Imager tool, which can be seen in Figure 8.

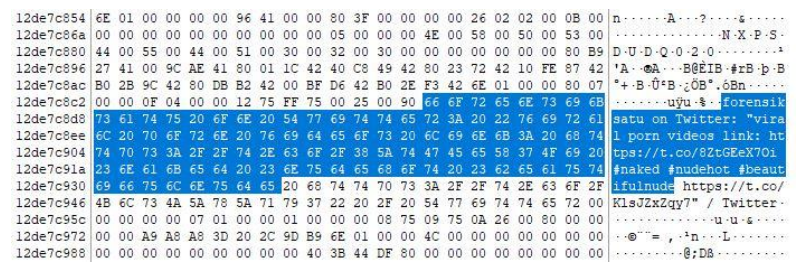

Figure 8. FTK Imager Results on Public Browsers

The search results found the text "viral porn videos link : https://t.co/8ZtGEeX7Oi \#naked \#nudehot \#beautifulnude" which comes from the @ forensiksatu account.

\subsubsection{DumpIT}

The acquisition result file with DumpIT was then analyzed using $\mathrm{XhD}$. The following is the evidence obtained which can be shown in Figure 9.

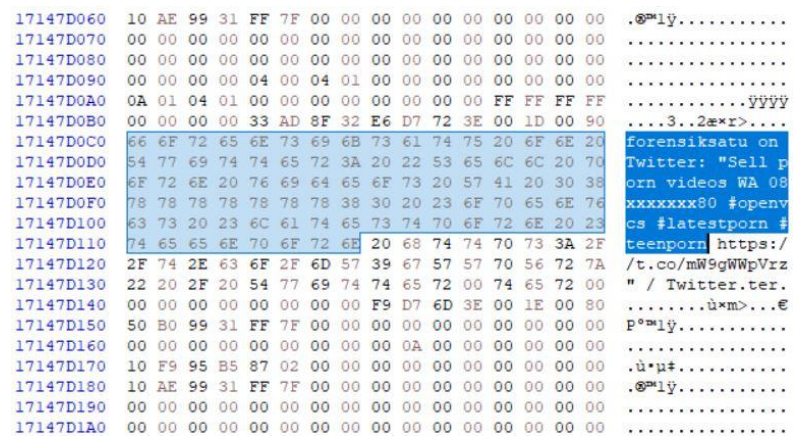

Figure 9. $\mathrm{XhD}$ results in public browsers

Figure 9 shows the text which also comes from the @ forensiksatu twitter account.

\subsubsection{Video Cache Viewer}

The results of the video cache viewer acquisition can be read with the help of Media Player Classic or MPC. The following is evidence that has been successfully obtained can be seen in Figure 10.

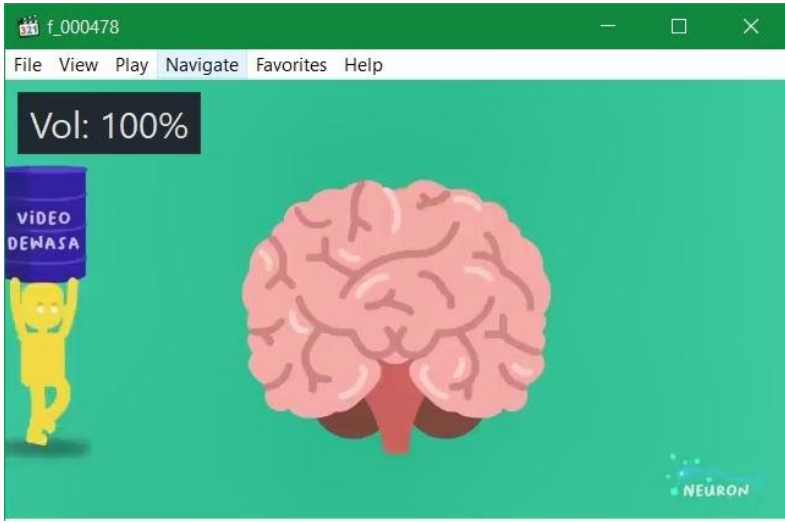

Figure 10. Public Browser Viewer Cache Video Results

It was found that the video came from Twitter with the name f_000478, which was $38 \mathrm{~KB}$, but the account that uploaded it was not known.

\subsubsection{Browser History Capturer}

The results of the acquisition with the browser history capturer can then be opened using its partner's tool, the browser history viewer. The evidence obtained can be seen in Figure 11.

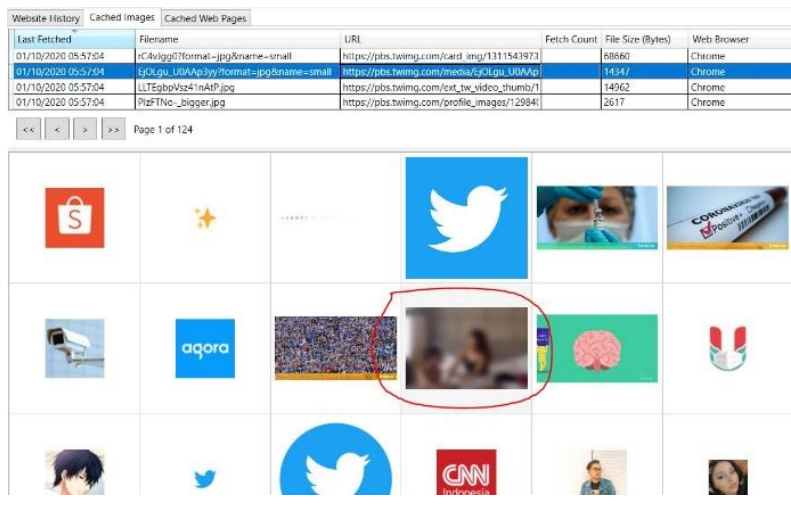

Figure 11. Browser History Capturer's Results on Public Browsers

It was found that there were images that also came from Twitter but there was no account that posted or accessed the images.

\subsubsection{Incognito Mode Browser}

Analysis using the incognito mode browser using the help of FTK Imager, XhD, Browser history capturer and media player classic tools

\subsubsection{Belkasoft Ram Capturer}

The results obtained using by the ram capturer tool were analyzed using the help of another forensic tool, namely ftk imager. The findings can be seen in Figure 12.

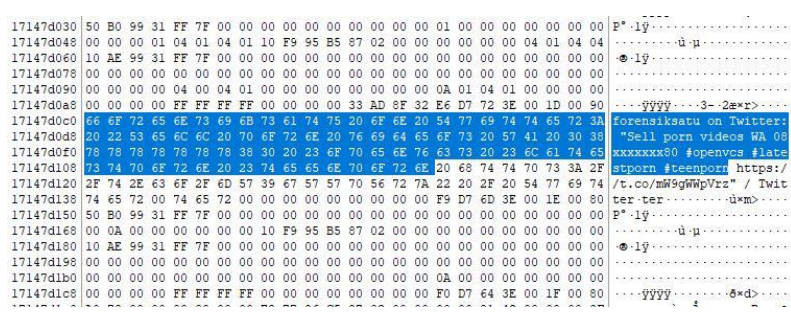

Figure 12. Ram Capturer Results on Incognito Browser 
The evidence obtained from Figure 12 is in the form of the text "sell porn videos WA $08 \times x \times x \times x \times 80$ " along with several hashtags used including \#openvcs, \#latestporn, and teenporn which comes from the @ forensiksatu account.

\subsubsection{DumpIT}

Evidence that was found with the help of the XhD tool can be seen in Figure 13.
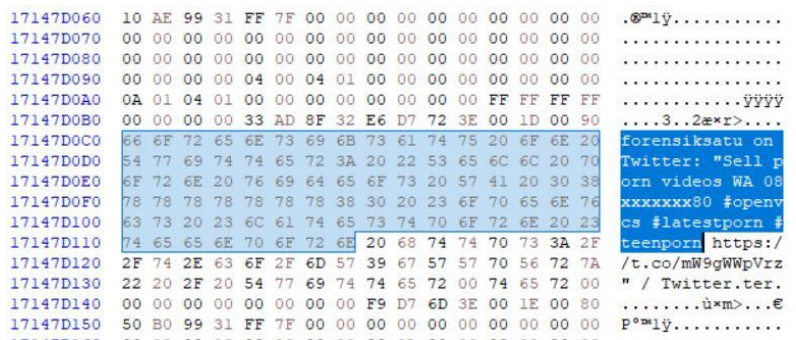

Figure 13. DumpIT results in incognito browser

Figure 13 shows that the text "sell porn videos WA 08xxxxxxx80 \#openves \# latestporn \#teenporn" was found which came from the @ forensiksatu twitter account. Evidence in the form of text has been successfully obtained using the help of the DumpIt and XhD tools. The use of the video cache viewer and browser history capturer tool did not succeed in finding the evidence that was sought, either in the form of photos or videos.

\subsubsection{Result}

The indicators used in the analysis include text posts, link posts, image posts, and video posts. A summary of the analysis results can be seen in table 3 .

\section{Table 3. List of Findings}

\begin{tabular}{|l|c|c|} 
Information & $\begin{array}{c}\text { Public Mode } \\
\text { Browser }\end{array}$ & $\begin{array}{c}\text { Private Mode } \\
\text { Browser }\end{array}$ \\
\hline Text Posts & $\checkmark$ & $\checkmark$ \\
\hline Link Posts & $\checkmark$ & $\checkmark$ \\
\hline Image Posts & $\checkmark$ & - \\
\hline Video Posts & $\checkmark$ & - \\
\hline
\end{tabular}

Based on table 3, the public mode browser managed to get all the evidence, such as text posts, link posts, images, and video posts. Meanwhile, the incognito mode browser only managed to get $50 \%$ of the data, namely for text posts and links. The remaining $50 \%$ cannot be found, namely in image posts and video posts.

\section{CONCLUSION}

Based on the results of research that have been carried out with the help of forensic tools and using two browser models, namely in public mode and incognito mode, it has succeeded in obtaining the evidence that is sought. The public mode browser was successful in getting all the evidence that was sought. The incognito mode browser managed to find $50 \%$ evidence, namely for text posts and link posts, while the remaining 50\% were not found, namely for image and video posts. The evidence found can then be used to report and assist in the trial process.

\section{REFERENCES}

[1] WeAreSocial, \& Hootsuite. Digital Report in 2019. Identified 22 October 2019, from https://wearesocial.com/blog/2019/01/global-digitalreport-2019
[2] Nurhairani, H., \& Riadi, I. (2019). Analysis Mobile Forensics on Twitter Application using the National Institute of Justice (NIJ) Method. International Journal of Computer Applications, 177 (27), 35-42. https://doi.org/10.5120/ijca2019919749

[3] Nurhairani, H., \& Riadi, I. (2019). Analysis Mobile Forensics on Twitter Application using the National Institute of Justice (NIJ) Method. International Journal of

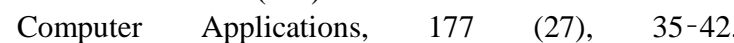
https://doi.org/10.5120/ijca2019919749

[4] Ketaren, E. 2016. Cybercrime, Cyber Space, and Cyber Law. Times, 5 (2), 35-42. Retrieved from http://stmiktime.ac.id/ejournal/index.php/jurnalTIMES/article/viewF ile/556/126

[5] Raka, ZD 2019. Spread of Illegal Content on Social Media (Case Study: Pornography on Bigo Live Application). 4 (1), 75-84. https://doi.org/.1037//00332909.I26.1.78

[6] Ahmad, MS 2017. Live Forensic Investigation from User's Side to Analyze Evil Twin-Based Man In The Middle Attack. Cell, 136 (4), 615-628. https://doi.org/10.1016/j.cell.2009.01.043

[7] Bintang, RAKN, Umar, R., \& Yudhana, U. 2018. Designing a live forensics comparison on social media security Instagram, Facebook and Twitter on Windows 10. Proceedings of the 9th SNST 2018, Faculty of Engineering, Wahid Hasyim University, 125-128.

[8] Faiz, MN, Umar, R., \& Yudhana, A. 2017. Implementation of Live Forensics for Browser Comparison on Email Security. JISKA (Journal of Informatics Sunan Kalijaga), 1 (3), 108. https://doi.org/10.14421/jiska.2017.13-02

[9] Yudhana, A., Riadi, I., \& Zuhriyanto, I. 2019. Live Forensics Analysis of Social Media Applications in Browsers Using the Digital Forensics Research Workshop (DFRWS) Method. 20 (2), 125-130

[10] Larasati, TD 2017. Live Forensics Analysis For Comparison of Instant Messenger Applications (Line, Facebook, and Telegram) on Windows 10 Operating System.

[11] Wijaya, ES, \& Subagyo, T. (2018). Analysis of Digital Evidence on Android Random Access Memory Using Live Forensic Method.

[12] Muhammad said Hasibuan. (2010). Design and Implementation of E-Journals as Improving Journal Services in Regional Kopertis 2. National Seminar on Information Technology Applications, 2010 (Snati), 4650 .

[13] Setiawan, D., Setiawan, R., Karunia, R., \& Wicaksana, IWS (2007). Comparing Web Browser Performance. Gunadarma University, 1 (1), 1-6.

[14] WeAreSocial, \& Hootsuite. Digital Report in 2019. Identified 22 October 2019, from https://wearesocial.com/blog/2019/01/global-digitalreport-2019

[15] Saifulloh, M., \& Ernanda, A. 2018. Communication Privacy Management for Adolescent Alter Ego Account Users on Twitter. WACANA, Scientific Journal of $\begin{array}{llll}\text { Communication } & \text { Sciences, } 17 & \text { (2), } 235 .\end{array}$ https://doi.org/10.32509/wacana.v17i2.652

[16] Ahmad, MS 2017. Live Forensic Investigation from 
User's Side to Analyze Evil Twin-Based Man In The Middle Attack. Cell, 136 (4), 615-628. https://doi.org/10.1016/j.cell.2009.01.043

[17] Marini, S. 2018. Digital Forensic Study in Regulation in Indonesia. National Seminar on Energy \& Technology, 103-106.

[18] Wahanggara, V., \& Prayudi, Y. (2015). System Call Based Malicious Software Detection System for Classification of Digital Evidence Using Support Vector Machine Method. SENTRA (National Seminar on Technology and Engineering), 1-8.

[19] Faiz, MN, Prabowo, WA, \& Sidiq, MF (2018). Digital
Forensic Investigation Comparative Study on Crime. Journal of Informatics, Information Systems, Software Engineering and Applications (INISTA), 1 (1), 54-62. https://doi.org/10.20895/INISTA.V1I1

[20] Law of the Republic of Indonesia Number 44 of 2008 concerning Pornography. (2008). 3 (2), 54-67. Retrieved from http://repositorio.unan.edu.ni/2986/1/5624.pdf

[21] Raka, ZD (2019). Distribution Of Illegal Content In Social Media (Case Study: Pornography On Bigo Live Application). 4 (1), 75-84. https://doi.org/.1037//00332909.I26.1.78 